\title{
Continuous passive motion not affect the knee motion and the surgical wound aspect after total knee arthroplasty
}

\author{
Sergi Gil-González ${ }^{1 *}\left(\mathbb{D}\right.$, Ricardo Andrés Barja-Rodríguez ${ }^{1}$, Antoni López-Pujol ${ }^{1}$, Hussein Berjaoui ${ }^{1}$, \\ Jose Enrique Fernández-Bengoa' ${ }^{1}$ Juan Ignacio Erquicia', Joan Leal-Blanquet ${ }^{1}$ and Xavier Pelfort $^{2}$
}

\begin{abstract}
Background: This study aimed to assess whether use of continuous passive motion (CPM) could improve range of motion in patients after total knee arthroplasty (TKA), if it could affect the surgical wound aspect (SWA) and if it could influence on pain management after TKA.

Methods: We randomized 210 patients in two groups, 102 patients in the CPM group, who received a standard rehabilitation protocol together with CPM application; and 108 patients in the no-CPM group, without CPM. Variables as knee motion (flexion, extension, range of motion) and pain were measured before surgery, on the 1st, 2nd and 3rd postoperative day, and in the 2nd, 6th, 12th and 24th postoperative weeks following TKA. The SWA was determined by the "surgical wound aspect score" (SWAS) in the next $48 \mathrm{~h}$ after surgery. This scale analyzes swelling, erythema, hematoma, blood drainage and blisters.

Results: There was an improvement in the knee motion over the course of follow-up in both groups, without significant difference in flexion parameter. We found no significant differences in the total score of SWA, except for hematoma, with less severity in the CPM group. Furthermore, we found no differences in the others SWAS parameters and pain.

Conclusions: The application of CPM does not provide benefit to our patients undergoing TKA in terms of either improved flexion mobility or decreased pain. No relationship was found between the use of CPM and the global score of SWA following a TKA, except for a decrease in hematoma appearance.
\end{abstract}

Keywords: Total knee arthroplasty, Continuous passive motion, Knee motion, Surgical wound aspect, Pain

\section{Introduction}

Knee osteoarthritis (OA) is a common disorder which generate severe pain, deformity and reduced knee mobility [1]. Total knee arthroplasty (TKA) is one of the best methods to treat knee OA, reducing pain, improving range of motion (ROM) and recovery of knee function $[2,3]$. Since the 1970 s, continuous passive motion (CPM)

\footnotetext{
*Correspondence: sergilg8@gmail.com

${ }^{1}$ Hospital Universitari Igualada, Consorci Sanitari de L'Anoia, Av. Catalunya, 11, 08700 Igualada, Barcelona, Spain
}

Full list of author information is available at the end of the article has been used to improve knee mobility and reduce stiffness after TKA, being part of the rapid postoperative recovery programs [4-6]. This intervention is provided by a machine that performs repetitive passive motion. The main benefits of CPM described in the literature are: improvement in the range of motion, decreased pain and reduced swelling, improvement in local circulation and reduced need for manipulation under anesthesia [7]. Nevertheless multiple studies show that the application of CPM does not have long-term advantages [4, 5, 8-14]. Moreover, some studies found no differences comparing original author(s) and the source, provide a link to the Creative Commons licence, and indicate if changes were made. The images or other third party material in this article are included in the article's Creative Commons licence, unless indicated otherwise in a credit line to the material. If material is not included in the article's Creative Commons licence and your intended use is not permitted by statutory regulation or exceeds the permitted use, you will need to obtain permission directly from the copyright holder. To view a copy of this licence, visit http://creativecommons.org/licenses/by/4.0/. The Creative Commons Public Domain Dedication waiver (http://creativeco mmons.org/publicdomain/zero/1.0/) applies to the data made available in this article, unless otherwise stated in a credit line to the data. 
the addition of CPM in these rehabilitation programs after TKA, versus patients who only received standard physical therapy alone [15-18]. Concerning shortterm benefits, in the last two decades the controversy has grown. Some studies suggest that patients who have received CPM after TKA have faster recovery in ROM $[4,9,11,14,17,19-22]$, less stiffness [22], less pain [23] and lower incidence of thrombophlebitis [21]. On the other hand, some studies find an increase in swelling [5, 13] and higher levels of pain [13]. Few articles analyze the relationship of wound healing and the use of CPM, being this association a fairly unknown topic [24]. Despite all the contradictory information, CPM is widely used in hospitals around the world as part of the standard postoperative management protocol for TKA [7].

The objectives of this study are to assess whether the use of CPM can improve range of motion in patients after TKA in comparison to a conventional self-assisted rehabilitation program without CPM, correlation between their use and the surgical wound aspect (SWA) and the influence in the level of pain.

\section{Materials and methods Participants}

Between January and December 2018, a prospective, randomized controlled trial was performed. All patients over 50 years of age and implanted with a primary TKA due to knee OA, were asked to enrol in our study. Patients with a high degree of deformity in the mechanical axis (over $15^{\circ}$ in varus or valgus deformity) or contracture knee flexion $\left(>20^{\circ}\right)$, inflammatory arthropathies, previous surgeries in the same knee (except simple arthroscopies), were excluded. All patients included signed an informed consent. The hospital's ethical committee approved the study (PR180/19). This study was performed in line with the principles of the Declaration of Helsinki.

\section{TKA procedure}

All the surgical procedures were carried by the same four senior consultants. All of them used two types of posterior stabilized cemented TKA: Stryker ${ }^{\circledR}$ Triathlon (Stryker, Mahwah, NJ, USA) or Surgival ${ }^{\circledR}$ Genutech (Surgival, Valencia, España) employing a medial parapatellar surgical approach. Intradural anaesthesia was used for all patients without regional nerve blocks and a pneumatic tourniquet was inflated to $300 \mathrm{mmHg}$ pressure before the incision and deflated at the end of surgery after skin closure. Local infiltration with 10-20 cc of Ropivacaine or Bupivacaine was administrated. A suction drain was introduced before wound closure and removed on the first postoperative day. Wound closure was made with simple stiches of coated vicryl ${ }^{\circledR}$ suture (polyglactin 910, Ethicon, Inc.) on subcutaneous tissue and skin with staples. Wound dressing was made with two gauzes and a soft bandage, removed at same time that suction drain, at the 24th postoperative hours. Patients received low weight heparin as venous thromboembolism prophylaxis for 30 days. Multimodal pain management protocol was applied in all patients.

\section{Randomization and application of the treatment}

Of the 230 eligible patients, 220 participants were assigned to each group according to a randomization list. (Fig. 1). The participants of the same group were cited in the same week to accomplish the treatment. That means that all the patients were surrounded with other patients that had the same rehabilitation program, in order to avoid possible information biases. One hundred and five patients were included in the CPM group, and they received a standardized rehabilitation program (SRP) with CPM. The others 115 patients received the same SRP without CPM (no-CPM group). The appointments were: (1) the same day of surgery, treatment of SRP was applied and it consist on assisted physical exercises carried out by a professional trained physiotherapist; (2) the following appointments were three times per day with at least $1 \mathrm{~h}$ on each occasion, and involving 20 repetitions for every exercise, including ankle mobility, active isometric contraction of the quadriceps, straight leg raises, quad sets and physiotherapist-assisted knee mobility exercises. In the CPM group, all patients started the CPM therapy the day of surgery and during two hours of therapy per three sessions at day until discharge. The degree of flexion was adjusted by the physiotherapist according to patient tolerance and progression at each session. Following discharge, a physiotherapist continued rehabilitation and knee mobility exercises without CPM at home for all patients in both groups, for one hour every day for the following ten consecutive days.

\section{Data collection}

The main variable was collected using double-blind by the rehabilitation consultant and the senior surgeon. Only physiotherapist knows the application or not of CPM. Knee ROM was measured using a long digital goniometer before surgery, on the 1st, 2nd and 3rd postoperative day, and in the 2nd, 6th, 12th and 24th postoperative weeks following TKA. The measurement was carried out by the rehabilitation consultant after the rehabilitation session of each day, and in the different visits of follow-up. The aspect of the surgical wound was assessed by the "surgical wound aspect score" (SWAS) in the next $48 \mathrm{~h}$ after surgery by the senior surgeon. This scale analyzes five parameters of wound characteristic: swelling, erythema, hematoma, blood drainage and blisters, obtaining a value from 0 to 2 points for each parameter depending on the 


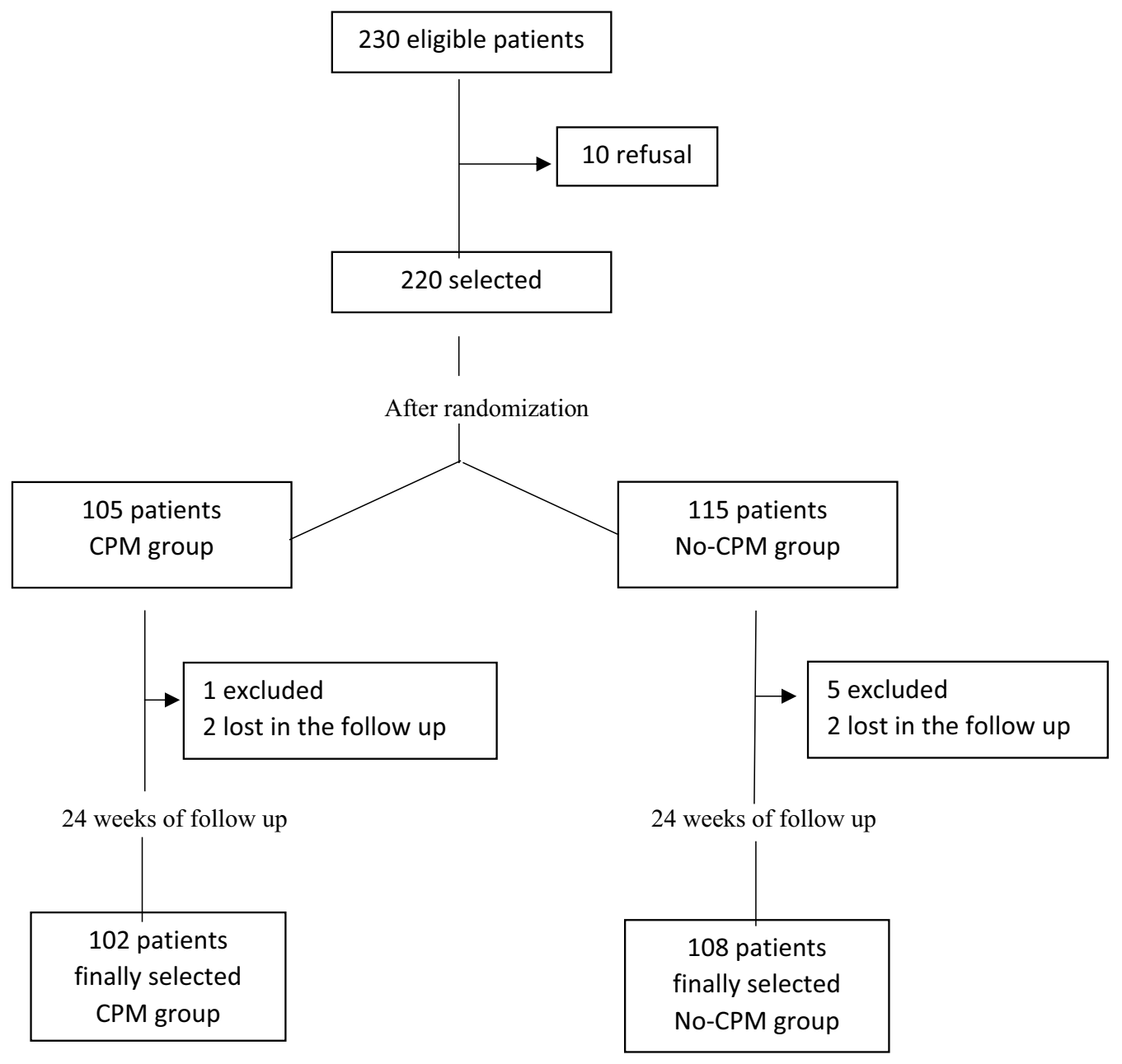

Fig. 1 Flowchart of the participants recruitment

severity of the injury and resulting a total score from 0 to 10 (being 10 the worst condition of the wound) [25]. Postoperative pain was measured by a rehabilitation consultant using the visual analog scale (VAS) (values from 0 to 10 ), prior surgery, on the 1st, 2nd and 3rd postoperative day, and in the 2nd, 6th, 12th and 24th postoperative week following TKA.

\section{Statistical analysis}

Descriptive results were calculated as means values and its standard deviations for continuous variables and a descriptive of the frequencies and its corresponding percentages for categorical variables. Differences in clinical characteristics and outcomes between study and control group were assessed using Mann-Whitney $U$ tests for continuous variables and chi-squared and Fisher's exact tests for categorical variables. In our statistical analyses, we accepted an alpha risk of 0.05 and a beta risk of 0.2 in a two-sided test. Anticipating a $20 \%$ drop-out rate, we aimed to recruit 187 consenting patients to achieve sufficient power. All analyses were performed based on intention-to-treat. All analyses were performed using IBM SPSS Statistics.

\section{Results}

The randomization procedure created demographically similar groups, without differences in preoperative parameters like age, gender, mobility (extension, flexion, $\mathrm{ROM}$ ) or pain (Table 1). The mean age of the patients was 74.23 (range: $55-87$ years), with a non-statistical significant higher percentage of females $(n=137 ; 65.2 \%)$ compared to males $(p=0.895)$.

In Fig. 1, we can observe that six patients were excluded from analysis because of postoperative complications that prevented application of the rehabilitation protocol. There were two patients with intraoperative fractures, two patients with deep infections that required two-stage revision, one with patellar 
Table 1 Patient demographic and preoperative data

\begin{tabular}{lccc}
\hline Variable & $\begin{array}{l}\text { CPM group } \\
(\boldsymbol{n}=\mathbf{1 0 5})\end{array}$ & $\begin{array}{l}\text { No-CPM group } \\
(\boldsymbol{n}=\mathbf{1 1 5})\end{array}$ & P Value \\
\hline Age (years) & $74.23(6.79)$ & $73.33(6.9)$ & 0.347 \\
Gender (F:M) & $67: 38$ & $70: 45$ & 0.895 \\
Pre-op mobility $\left(^{\circ}\right)$ & & & \\
$\quad$ Extension & $3.11(4,29)$ & $3.53(5.63)$ & 0.540 \\
$\quad$ Flexion & $110.48(11.92)$ & $109.21(12.32)$ & 0.445 \\
$\quad$ Full ROM & $107.38(13.28)$ & $105.67(15.43)$ & 0.393 \\
Pre-op VAS & $4.4(2.4)$ & $3.9(2.4)$ & 0.204 \\
\hline
\end{tabular}

Values shown are mean (SD) $p$ value significant at 0.05

tendon rupture and one that death during the followup. In addition, information from four patients who not completed follow-up, two in each group, was also excluded from the database.

Results comparing knee mobility are shown in Table 2. We found an improvement of flexion, extension and ROM, in both groups along the process between admission and discharge and over the course of followup $(p<0.010)$. ROM improved throughout the followup in both groups after the surgery (Fig. 2). However, the improvement in the CPM group was greater than the no-CPM group through all follow-up, being significant in the first and second postoperative day and in the second postoperative week of follow-up. At the 24th postoperative week, we observed a persistent improvement in ROM in the CPM group $\left(6^{\circ}\right.$ greater in with respect no-CPM group), although this difference was not significant $(p=0.056)$. The most relevant parameter in the application of CPM was highlighting flexion. At the time of discharge, both groups again had similar results, with a mean flexion of $91.38^{\circ}$ (SD 9.4) in the CPM group and $92.23^{\circ}$ (SD 10.06) in the no-CPM group $(p=0.769)$. There were no significant differences between groups at any of the time points evaluated (Table 2). At the last follow-up, 24th postoperative week, mean flexion in the CPM group was $121.39^{\circ}$ (SD 8.92) and $118.73^{\circ}$ (SD 9.92) in the no-CPM group $(p=0.066)$ (Fig. 3). Concerning the extension, we did not observe any significant difference between groups. No patient had knee stiffness that required any surgical procedure or forced mobilization.

Regarding the surgical wound, we did not find any difference in the total score of SWAS between CPM or in no-CPM groups $(p=0.289)$ (Table 3$)$. However, when we analyzed the individual parameters of the SWAS, we found significantly fewer patients with a worse hematoma in the CPM group compared to the no-CPM group $(p=0.028)$. Despite this, any patient required surgical drainage or had skin necrosis due to the hematoma.
Table 2 Comparison of postoperative knee mobility in degrees in CPM and no-CPM groups

\begin{tabular}{|c|c|c|c|}
\hline Follow-up & CPM group & No-CPM group & $P$ value \\
\hline \multicolumn{4}{|l|}{ Day 1} \\
\hline Extension & $7.48(8.51)$ & $9.14(8.60)$ & 0.164 \\
\hline Flexion & 77.83 (13.32) & 74.27 (16.05) & 0.083 \\
\hline Full ROM & 70.34 (13.62) & $64.53(17.04)$ & 0.007 \\
\hline \multicolumn{4}{|l|}{ Day 2} \\
\hline Extension & $4.52(5.93)$ & $5.83(6.57)$ & 0.130 \\
\hline Flexion & $86.59(11.16)$ & $84.33(11.90)$ & 0.158 \\
\hline Full ROM & $82.07(11.93)$ & 77.76 (15.01) & 0.023 \\
\hline \multicolumn{4}{|l|}{ Day 3} \\
\hline Extension & $1.11(3.29)$ & $2.7(5.33)$ & 0.064 \\
\hline Flexion & $91.38(9.40)$ & $92.23(10.06)$ & 0.769 \\
\hline Full ROM & 89.65 (13.75) & 86.08 (15.49) & 0.088 \\
\hline \multicolumn{4}{|l|}{ Week 2} \\
\hline Extension & $0.84(3.19)$ & $1.90(4.99)$ & 0.113 \\
\hline Flexion & $97.01(10.40)$ & $94.89(12.10)$ & 0.180 \\
\hline Full ROM & $94.57(11.34)$ & $88.62(20.20)$ & 0.010 \\
\hline \multicolumn{4}{|l|}{ Week 6} \\
\hline Extension & $0.31(1.65)$ & $0.54(2.42)$ & 0.484 \\
\hline Flexion & $109.70(10.35)$ & $108.72(11.84)$ & 0.530 \\
\hline Full ROM & 105.91 (18.61) & $103.08(21.90)$ & 0.315 \\
\hline \multicolumn{4}{|l|}{ Week 12} \\
\hline Extension & $1.02(2.74)$ & $2.05(4.16)$ & 0.060 \\
\hline Flexion & $116.17(9.19)$ & 115.44 (10.77) & 0.603 \\
\hline Full ROM & $112.89(18.71)$ & $109.19(24.75)$ & 0.225 \\
\hline \multicolumn{4}{|l|}{ Week 24} \\
\hline Extension & $0.65(2.51)$ & $1.23(3.43)$ & 0.175 \\
\hline Flexion & $121.39(8.92)$ & $118.73(9.92)$ & 0.066 \\
\hline Full ROM & 118.73 (19.59) & $112.07(27.08)$ & 0.056 \\
\hline
\end{tabular}

Values shown are mean (SD) $p$ value significant at 0.05

From surgery, pain levels experienced by the patients were similar, with a comparable decrease over time in both groups (Table 4).

\section{Discussion}

The main findings of our study are the lack of benefit to the knee flexion, surgical wound healing and reduction pain of the use of CPM. Our results are in agreement with many recent studies $[20,26]$ where they found no improvement on knee flexion due to application of CPM. We found no significant difference between groups in extension or flexion. However, we found a suggestion of higher degrees value of ROM in CPM group than in noCPM group, observing around five degrees of difference in favor of the CPM group, especially on the 1st postoperative day or 2nd postoperative week, however we did not consider that difference could represent a significant clinical improvement. These results are in line with those 


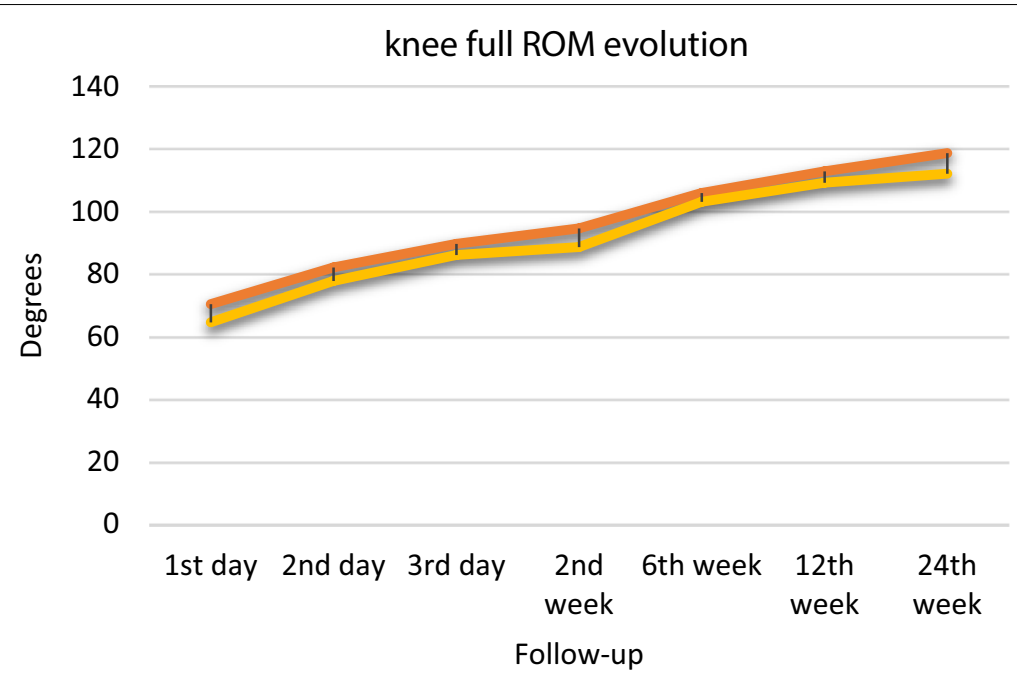

Fig. 2 Evolution of knee full ROM trough follow-up in CPM and no-CPM groups

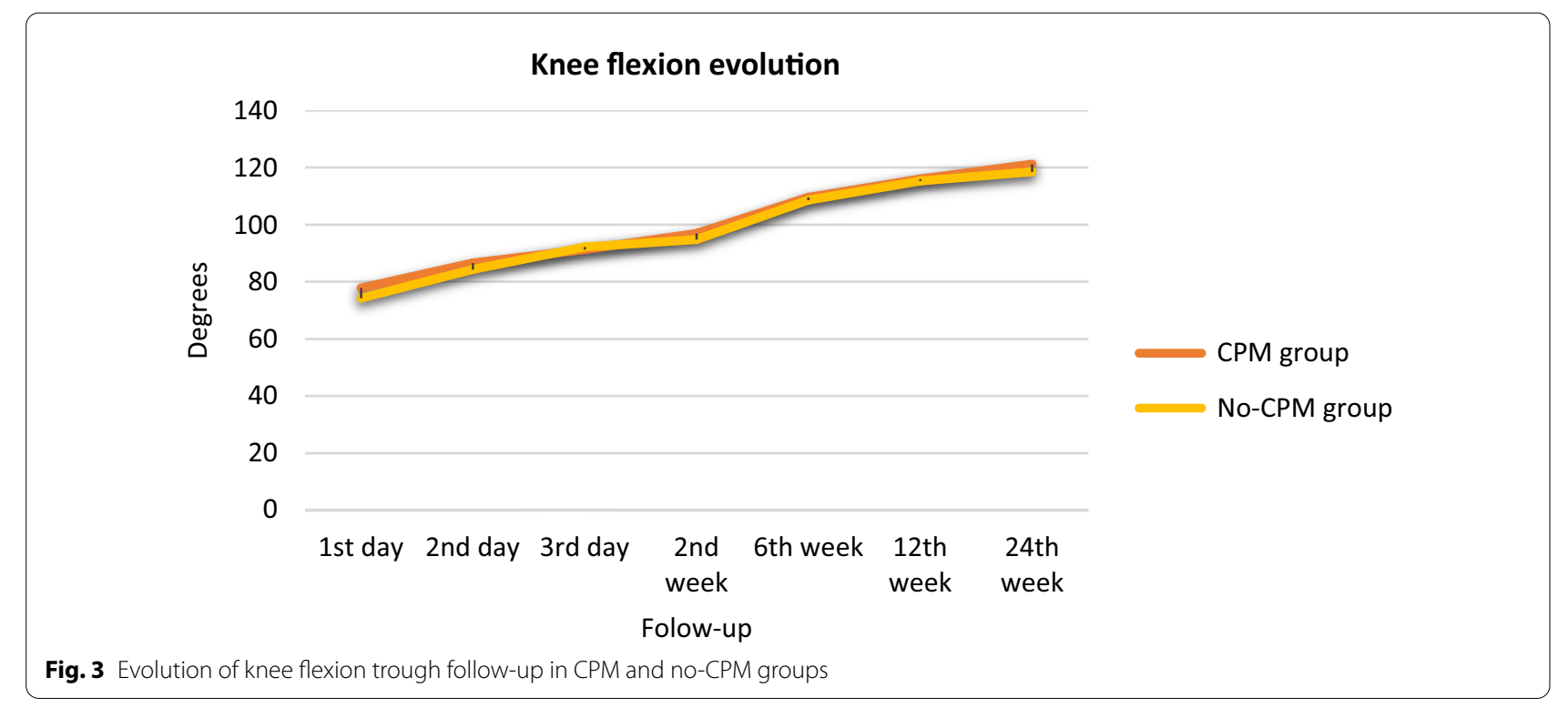

reported in the Cochrane review [20], with a difference of two degrees to six in favor of CPM application in knee flexion between CPM and non-CPM group. However, some studies found different results to ours. McInnes et al. [27] or Lenssen et al. [28] described an increment in active flexion on the earlier postoperative days, in patients who received CPM, but not long-term benefit. Liao et al. [29] obtain an improvement on ROM at 3rd and 6th month follow-up with an early application of CPM with initial high flexion angle and rapid progress.

We observed a similar improvement from the 1st postoperative day to 24th postoperative week of followup in both groups. All our patients had a consistent improvement in ROM, both groups achieving a mean flexion of $90^{\circ}$ at 2 nd postoperative week and a mean flexion of $115^{\circ}$ at 12 th postoperative week. They recovered preoperatory levels of knee range of motion between 6 and 12th postoperative week. But the use of CPM in the post-TKA has remained controversial. Several studies have reported benefits of CPM during the acute phase $[10,20,29,30]$, while others report the absence of benefits [11, 26, 31]. But we should be careful on interpreting these different studies, because there is a high degree of heterogeneity in rehabilitation protocols, with different frequency and duration of CPM applied, anesthetic and analgesic drugs used, among 
Table 3 Distribution of patients relative to the SWAS and comparison of CPM and no-CPM groups

\begin{tabular}{|c|c|c|c|}
\hline SWAS & CPM group & No-CPM group & $P$ value \\
\hline Swelling & & & 0.157 \\
\hline 0 & 27 (26.5\%) & $17(15.8 \%)$ & \\
\hline 1 & 57 (55.9\%) & 70 (64.8\%) & \\
\hline 2 & $18(17.6 \%)$ & 21 (19.4\%) & \\
\hline Erythema & & & 0.463 \\
\hline 0 & 95 (93.1\%) & 97 (89.8\%) & \\
\hline 1 & 7 (6.9\%) & $11(10.2 \%)$ & \\
\hline 2 & 0 & 0 & \\
\hline Hematoma & & & 0.028 \\
\hline 0 & $58(56.9 \%)$ & 44 (40.8\%) & \\
\hline 1 & $36(35.3 \%)$ & 46 (42.6\%) & \\
\hline 2 & $8(7.8 \%)$ & 18 (16.6\%) & \\
\hline Drainage & & & 0.558 \\
\hline 0 & 68 (66.7\%) & 73 (67.6\%) & \\
\hline 1 & $28(27.5 \%)$ & 25 (23.2\%) & \\
\hline 2 & $6(5.9 \%)$ & $10(9.2 \%)$ & \\
\hline Blisters & & & 0.175 \\
\hline 0 & 98 (96.1\%) & 98 (90.7\%) & \\
\hline 1 & $2(2 \%)$ & $8(7.4 \%)$ & \\
\hline 2 & $2(2 \%)$ & $2(1.9 \%)$ & \\
\hline Total & & & 0.289 \\
\hline 0 & $11(10.8 \%)$ & $5(4.6 \%)$ & \\
\hline 1 & $36(35.3 \%)$ & 29 (26.9\%) & \\
\hline 2 & $25(24.5 \%)$ & 34 (31.5\%) & \\
\hline 3 & $12(11.8 \%)$ & $16(14.8 \%)$ & \\
\hline 4 & $12(11.8 \%)$ & 11 (10.2\%) & \\
\hline 5 & $3(2.9 \%)$ & 7 (6.5\%) & \\
\hline 6 & $2(2 \%)$ & $4(3.7 \%)$ & \\
\hline 7 & - & $2(1.9 \%)$ & \\
\hline 8 & $1(1 \%)$ & - & \\
\hline 9 & - & - & \\
\hline 10 & - & - & \\
\hline
\end{tabular}

SWAS, Surgical wound aspect scale

Values shown are number and percentage of patients for each parameter and score level. $P$ value significant at 0.05

Table 4 Comparison of postoperative pain in CPM and no-CPM groups

\begin{tabular}{llll}
\hline VAS & CPM group & No-CPM group & P Value \\
\hline Day 1 & $6.4(1.9)$ & $6.5(2.0)$ & 0.773 \\
Day 2 & $5.6(1.8)$ & $5.8(1.8)$ & 0.497 \\
Day 3 & $4.9(1.7)$ & $5.0(1.7)$ & 0.831 \\
Week 2 & $4.4(1.9)$ & $4.4(1.8)$ & 0.997 \\
Week 6 & $2.3(2.0)$ & $2.4(2.0)$ & 0.545 \\
Week 12 & $1.1(1.6)$ & $1.1(1.9)$ & 0.914 \\
Week 24 & $0.5(1.1)$ & $0.6(1.3)$ & 0.598 \\
\hline
\end{tabular}

VAS, Visual analog scale (0-10)

Values shown are mean (SD) $p$ value significant at 0.05 other. In our study, we maintained the same fast recovery program, with the exception of the use and duration of CPM application. In the publication of Boese et al. [23] they compare three groups with different CPM application (full moving CPM, 90 degrees non-moving CPM, no CPM) at least two postoperative days, finding no differences between them in terms of ROM. In Joshi et al. [32] they used a similar rehabilitation program, but with a very different anesthesia protocol with peripheral nerve block option, and they found no benefits in CPM use. Richter et al. [33] compare two groups with more days of CPM application than us (10 post-op days), without differences in terms of ROM or clinical and functional results. Wirries et al. [34] showed same results at long-term follow-up, without clinical advantages in mobility and functional results.

In our study, we did not found repercussion of the CPM rehabilitation protocol to the SWA, except for hematoma. Our SWA analysis revealed a significantly increased number of patients in the no-CPM group with hematoma compared to the CPM group. This could be possible due to CPM may reduce swelling due to its pumping action, pushing blood and edema fluid away from the joint and periarticular tissues [5, 35]. McInnes et al. [27] and Montgomery et al. [36] observed a decrease in swelling with the use of CPM. However, we did not observe any difference in swelling in our SWA scores, according to other studies $[5,11,23]$. With respect to another SWA parameters, i.e., bleeding, Maniar et al. [5] concluded that CPM may tend to lead to a greater incidence of wound staining according to their classification. We did not see any such difference. Johnson et al. [37] pointed out that the transcutaneous oxygen tension on the lateral aspect of incision might decrease as the knee flexed more than $40^{\circ}$. In our patients, with more than $40^{\circ}$ on flexion in the $1^{\text {st }}$ postoperative day, no skin necrosis was observed. Other studies suggest a positive benefit of CPM in biological tissues with respect to tissue healing, limb edema, hemarthrosis and knee function [10, 35, 38]. Our results are partly in agreement with these findings.

In terms of pain, the patients included in this study had a progressive reduction in pain during the course of follow-up, with no difference within groups. However, Denis et al. [17] showed that use of CPM might be beneficial for pain relief in the early postoperative stage. Cochrane review [20] find only low-quality evidence for the reduction in pain using CPM, with a mean reduction scores of 0.4 points (10 point scale) at 6 th postoperative week, whereas in our study, we saw a difference within groups of only 0,1 points.

In addition, the Cochrane review [20] find that CPM reduced the possibility of performing a forced mobilization under anesthesia because of the stiffness after 
surgery. In our study, no patients required this kind of procedure in any of both groups.

The main strength of our study is one of the largest sample size studies in the literature, excluding metanalysis. Furthermore, the prospective and randomized controlled trial design strength the results. Nevertheless, this study has few limitations. The grouping of the participants to CPM used could not be blinded because of the nature of CPM device. In addition, some patients had undergone a previous TKA before this study, and thus knew that use of a CPM device was standard, potentially resulting in an effect that could produce an uncontrollable patient suggestion. SWA score, used for assess surgical wound aspect, even publicated it is not validated [25].

\section{Conclusions}

The use of CPM under this protocol does not provide clinical improvement in terms of knee flexion, appearance of surgical wound or reduction pain after TKA, except for hematoma where we observed a decreased risk of postoperative using CPM.

\section{Abbreviations}

CPM: Continuous passive motion; TKA: Total knee arthroplasty; SWA: Surgical wound aspect; SWAS: Surgical wound aspect score; OA: Osteoarthritis; ROM: Range of motion; SRP: Standardized rehabilitation program.

\section{Acknowledgements}

The authors wish to acknowledge Ms. Marta Banqué, for her participation in the statistical analysis of the study; Ms. Saron Bosch and Ms. Sara Torres for their help in the post-operative physiotherapy treatment of patients; Mr. Chris McKinnell, providing language help; Ms. Angela Zumel for their critical revision of manuscript.

\section{Authors' contribution}

All authors contributed to the study conception and design. Material preparation, data collection and analysis were performed by SGG, ABR, ALP, HB, JEFB, $J I E$, JLB and XP. The first draft of the manuscript was written by SGG and ABR with the supervision by XP, and all authors commented on previous versions of the manuscript. All authors read and approved the final manuscript.

\section{Funding}

No funding was received for conducting this study.

\section{Availability of data and materials}

The datasets used and/or analyzed during the current study are available from the corresponding author on reasonable request.

\section{Declarations}

\section{Ethics approval and consent to participate}

Ethic Committee of Hospital Universitari de Bellvitge, Hospitalet de Llobregat, Barcelona (Spain) approved project ref. PR180/19 (code PRCSA0117). This study was performed in line with the principles of the Declaration of Helsinki.

\section{Consent for publication}

Informed consent was obtained from all individual participants included in the study.

\section{Competing interests}

Each author certifies that he has no commercial associations that might pose a competing interest in connection with the submitted article.

\section{Author details}

${ }^{1}$ Hospital Universitari Igualada, Consorci Sanitari de L'Anoia, Av. Catalunya, 11, 08700 Igualada, Barcelona, Spain. ${ }^{2}$ Hospital Universitari Parc Taulí, Parc Taulí, 1 , 08208 Sabadell, Barcelona, Spain.

Received: 8 November 2021 Accepted: 3 January 2022

Published online: 15 January 2022

\section{References}

1. Noble PC, Gordon MJ, Weiss JM, Reddix RN, Conditt MA, Mathis KB. Does total knee replacement restore normal knee function? Clin Orthop. 2005;431:157-65. https://doi.org/10.1097/01.blo.0000150130.03519.fb.

2. Carr AJ, Robertsson O, Graves S, Price AJ, Arden NK, Judge A, et al. Knee replacement. Lancet Lond Engl. 2012;379:1331-40. https://doi.org/10. 1016/S0140-6736(11)60752-6.

3. Rowe PJ, Myles CM, Walker C, Nutton R. Knee joint kinematics in gait and other functional activities measured using flexible electrogoniometry: how much knee motion is sufficient for normal daily life? Gait Posture. 2000;12:143-55. https://doi.org/10.1016/s0966-6362(00)00060-6.

4. Leach W, Reid J, Murphy F. Continuous passive motion following total knee replacement: a prospective randomized trial with follow-up to 1 year. Knee Surg Sports Traumatol Arthrosc Off J ESSKA. 2006;14:922-6. https://doi.org/10.1007/s00167-006-0042-9.

5. Maniar RN, Baviskar JV, Singhi T, Rathi SS. To use or not to use continuous passive motion post-total knee arthroplasty presenting functional assessment results in early recovery. J Arthroplasty. 2012;27:193-200.e1. https:// doi.org/10.1016/j.arth.2011.04.009.

6. Salter RB, Simmonds DF, Malcolm BW, Rumble EJ, MacMichael D, Clements ND. The biological effect of continuous passive motion on the healing of full-thickness defects in articular cartilage. An experimental investigation in the rabbit. J Bone Joint Surg Am. 1980;62:1232-51.

7. Salter RB. Continuous passive motion: from origination to research to clinical applications.J Rheumatol. 2004:31:2104-5.

8. Bennett LA, Brearley SC, Hart JAL, Bailey MJ. A comparison of 2 continuous passive motion protocols after total knee arthroplasty: a controlled and randomized study. J Arthroplasty. 2005;20:225-33. https://doi.org/10. 1016/j.arth.2004.08.009.

9. Beaupré LA, Davies DM, Jones CA, Cinats JG. Exercise combined with continuous passive motion or slider board therapy compared with exercise only: a randomized controlled trial of patients following total knee arthroplasty. Phys Ther. 2001;81:1029-37.

10. Brosseau L, Milne S, Wells G, Tugwell P, Robinson V, Casimiro L, et al. Efficacy of continuous passive motion following total knee arthroplasty: a metaanalysis. J Rheumatol. 2004;31:2251-64.

11. Chen L-H, Chen C-H, Lin S-Y, Chien S-H, Su JY, Huang C-Y, et al. Aggressive continuous passive motion exercise does not improve knee range of motion after total knee arthroplasty. J Clin Nurs. 2013;22:389-94. https:// doi.org/10.1111/j.1365-2702.2012.04106.x.

12. He ML, Xiao ZM, Lei M, Li TS, Wu H, Liao J. Continuous passive motion for preventing venous thromboembolism after total knee arthroplasty. Cochrane Database Syst Rev. 2012;1:CD008207. https://doi.org/10.1002/ 14651858.CD008207.pub2.

13. Pope RO, Corcoran S, McCaul K, Howie DW. Continuous passive motion after primary total knee arthroplasty. Does it offer any benefits? J Bone Joint Surg Br. 1997;79:914-7. https://doi.org/10.1302/0301-620x.79b6. 7516.

14. Ritter MA, Gandolf VS, Holston KS. Continuous passive motion versus physical therapy in total knee arthroplasty. Clin Orthop. 1989;244:239-43.

15. Lau SK, Chiu KY. Use of continuous passive motion after total knee arthroplasty. J Arthroplasty. 2001;16:336-9. https://doi.org/10.1054/arth.2001. 21453.

16. Davies DM, Johnston DWC, Beaupre LA, Lier DA. Effect of adjunctive range-of-motion therapy after primary total knee arthroplasty on the use of health services after hospital discharge. Can J Surg J Can Chir. 2003:46:30-6.

17. Denis M, Moffet H, Caron F, Ouellet D, Paquet J, Nolet L. Effectiveness of continuous passive motion and conventional physical therapy after total knee arthroplasty: a randomized clinical trial. Phys Ther. 2006;86:174-85. 
18. Hewitt B, Shakespeare D. Flexion vs. extension: a comparison of postoperative total knee arthroplasty mobilisation regimes. The Knee. 2001;8:305-9. https://doi.org/10.1016/s0968-0160(01)00110-7.

19. Alkire MR, Swank ML. Use of inpatient continuous passive motion versus no CPM in computer-assisted total knee arthroplasty. Orthop Nurs. 2010;29:36-40. https://doi.org/10.1097/NOR.0b013e3181c8ce23.

20. Harvey LA, Brosseau L, Herbert RD. Continuous passive motion following total knee arthroplasty in people with arthritis. Cochrane Database Syst Rev. 2014. https://doi.org/10.1002/14651858.CD004260.pub3.

21. Vince KG, Kelly MA, Beck J, Insall JN. Continuous passive motion after total knee arthroplasty. J Arthroplasty. 1987;2:281-4. https://doi.org/10.1016/ s0883-5403(87)80060-8.

22. Ververeli PA, Sutton DC, Hearn SL, Booth RE, Hozack WJ, Rothman RR. Continuous passive motion after total knee arthroplasty. Analysis of cost and benefits. Clin Orthop 1995; 208-15.

23. Boese CK, Weis M, Phillips T, Lawton-Peters S, Gallo T, Centeno L. The efficacy of continuous passive motion after total knee arthroplasty: a comparison of three protocols. J Arthroplasty. 2014;29:1158-62. https:// doi.org/10.1016/j.arth.2013.12.005.

24. Goletz TH, Henry JH. Continuous passive motion after total knee arthroplasty. South Med J. 1986;79:1116-20. https://doi.org/10.1097/00007611198609000-00019.

25. Torres-Claramunt R, Gil-González S, Leal J, Hinarejos P, Pelfort X, Puig L, et al. A new score assessing the surgical wound of a TKA and its relation with pain, infection and functional outcome. Acta Orthop Belg. 2015;81:713-9.

26. Yang $X$, Li G-H, Wang H-J, Wang C-Y. Continuous passive motion after total knee arthroplasty: a systematic review and meta-analysis of associated effects on clinical outcomes. Arch Phys Med Rehabil. 2019;100:1763-78. https://doi.org/10.1016/j.apmr.2019.02.001.

27. Mclnnes J, Larson MG, Daltroy LH, Brown T, Fossel AH, Eaton HM, et al. A controlled evaluation of continuous passive motion in patients undergoing total knee arthroplasty. JAMA. 1992;268:1423-8. https://doi.org/10. 1001/jama.268.11.1423.

28. Lenssen TAF, van Steyn MJA, Crijns YHF, Waltjé EMH, Roox GM, Geesink RJT, et al. Effectiveness of prolonged use of continuous passive motion (CPM), as an adjunct to physiotherapy, after total knee arthroplasty. BMC Musculoskelet Disord. 2008;9:60. https://doi.org/10.1186/1471-2474-9-60.

29. Liao C-D, Tsauo J-Y, Huang S-W, Chen H-C, Chiu Y-S, Liou T-H. Preoperative range of motion and applications of continuous passive motion predict outcomes after knee arthroplasty in patients with arthritis. Knee Surg Sports Traumatol Arthrosc Off J ESSKA. 2019;27:1259-69. https://doi.org/ 10.1007/s00167-018-5257-z.

30. Bade MJ, Kittelson JM, Kohrt WM, Stevens-Lapsley JE. Predicting functional performance and range of motion outcomes after total knee arthroplasty. Am J Phys Med Rehabil. 2014;93:579-85. https://doi.org/10. 1097/PHM.0000000000000065.

31. Chaudhry H, Bhandari M. Cochrane in CORR $\left({ }^{\circledR}\right)$ : continuous passive motion following total knee arthroplasty in people with arthritis (review). Clin Orthop. 2015;473:3348-54. https://doi.org/10.1007/ s11999-015-4528-y.

32. Joshi RN, White PB, Murray-Weir M, Alexiades MM, Sculco TP, Ranawat AS. Prospective randomized trial of the efficacy of continuous passive motion post total knee arthroplasty: experience of the hospital for special surgery. J Arthroplasty. 2015;30:2364-9. https://doi.org/10.1016/j.arth. 2015.06.006.

33. Richter M, TrzeciakT, Kaczmarek M. Effect of continuous passive motion on the early recovery outcomes after total knee arthroplasty. Int Orthop. 2021. https://doi.org/10.1007/s00264-021-05245-5.

34. Wirries N, Ezechieli M, Stimpel K, Skutek M. Impact of continuous passive motion on rehabilitation following total knee arthroplasty. Physiother Res Int J Res Clin Phys Ther. 2020;25: e1869. https://doi.org/10.1002/pri.1869.

35. O'Driscoll SW, Giori NJ. Continuous passive motion (CPM): Theory and principles of clinical application. J Rehabil Res Dev. 2000;37:179-88.

36. Montgomery F, Eliasson M. Continuous passive motion compared to active physical therapy after knee arthroplasty: similar hospitalization times in a randomized study of 68 patients. Acta Orthop Scand. 1996;67:7-9. https://doi.org/10.3109/17453679608995599.

37. Johnson DP. The effect of continuous passive motion on woundhealing and joint mobility after knee arthroplasty. J Bone Joint Surg Am. 1990;72:421-6
38. Salter RB. The biologic concept of continuous passive motion of synovial joints. The first 18 years of basic research and its clinical application. Clin Orthop. 1989:242:12-25.

\section{Publisher's Note}

Springer Nature remains neutral with regard to jurisdictional claims in published maps and institutional affiliations.
Ready to submit your research? Choose BMC and benefit from:

- fast, convenient online submission

- thorough peer review by experienced researchers in your field

- rapid publication on acceptance

- support for research data, including large and complex data types

- gold Open Access which fosters wider collaboration and increased citations

- maximum visibility for your research: over $100 \mathrm{M}$ website views per year

At BMC, research is always in progress.

Learn more biomedcentral.com/submissions 